\title{
Demonstration of IS7 I I transposition in Brucella ovis and Brucella pinnipedialis
}

\author{
Alain A Ocampo-Sosa and Juan M García-Lobo*
}

\author{
Address: Departamento de Biología Molecular, Universidad de Cantabria, Instituto de Biomedicina y Biotecnología de Cantabria, IBBTEC. (CSIC \\ - Universidad de Cantabria - IDICAN), Santander. Spain \\ Email: Alain A Ocampo-Sosa - alainocampo@hotmail.com; Juan M García-Lobo* - jmglobo@unican.es \\ * Corresponding author
}

Published: 24 January 2008

BMC Microbiology 2008, 8:17 doi:10.1/86/147|-2180-8-17

Received: 24 July 2007

Accepted: 24 January 2008

This article is available from: http://www.biomedcentral.com/I47I-2/80/8/17

(C) 2008 Ocampo-Sosa and García-Lobo; licensee BioMed Central Ltd.

This is an Open Access article distributed under the terms of the Creative Commons Attribution License (http://creativecommons.org/licenses/by/2.0), which permits unrestricted use, distribution, and reproduction in any medium, provided the original work is properly cited.

\begin{abstract}
Background: The Brucella genome contains an insertion sequence (IS) element called IS7II or IS650I, which is specific to the genus. The copy number of IS7II varies in the genome of the different Brucella species, ranging from 7 in B. abortus, B. melitensis and B. suis to more than 30 in $B$. ovis and in Brucella strains isolated from marine mammals. At present, there is no experimental evidence of transposition of IS7II, but the occurrence of this element with a high copy number in some species, and the isolation of Brucella strains with "ectopic" copies of IS7 I I suggested that this IS could still transpose.
\end{abstract}

Results: In this study we obtained evidence of transposition of IS7II from the B. ovis and B. pinnipedialis chromosomes by using the "transposon trap" plasmid pGBGI. This plasmid expresses resistance to tetracycline only if the repressor gene that it contains is inactivated. The strains $B$. melitensis 16 M, B. abortus RB5 I, B. ovis BOC22 (field strain) and B. pinnipedialis B2/94, all containing the plasmid PGBGI, were grown in culture media with tetracycline until the appearance of tetracycline resistant mutants $\left(T c^{R}\right)$. $T c^{R}$ mutants due to ISTII transposition were only detected in B. ovis and B. pinnipedialis strains.

Conclusion: Four different copies of IS7 I I were found to transpose to the same target sequence in the plasmid PGBGI. This demonstrated that IS7II are active in vivo, specially in Brucella species with a high number of IS7I I copies as B. ovis and B. pinnipedialis.

\section{Background}

Bacteria in the genus Brucella are the etiological agents of brucellosis, one of the most important zoonotic diseases, affecting human and domestic animals of high economic and social value. The genus contains several species that are defined mainly on the basis of animal host specificity [1]. A growing interest in development of tools for molecular epidemiology and control of brucellosis has resulted in a large amount of published genome sequence data. The complete genome sequences of B. melitensis [2], B. suis
[3], and two B. abortus strains $[4,5]$ are already published, and the genome sequences of $B$. ovis, $B$. canis and the $B$. abortus vaccine strain S19 are also completed but not published yet.

The genus Brucella bears an Insertion sequence (IS) element, originally detected in Brucella ovis as a repeated polymorphic DNA sequence in 1990 [6]. Subsequently, this repeat was proposed to be an IS based on its genetic organisation, which is similar to that of some elements 
described before, and named as IS711 [7] or IS6501 [8]. IS elements are defined as small segments of DNA with a simple genetic organisation and capable of inserting at multiple sites into target DNA molecules. The best known ISs are those of the Gram-negative bacteria, but these mobile elements have been widely reported in a variety of bacterial genera. A compilation of the available data on insertion sequences can be found in the IS database [9].

IS711 is an 842 bp element bounded by 20 bp imperfect inverted repeats. This IS contains two overlapping open reading frames, which are believed to translate into a single polypeptide by means of a -1 frameshift of the translation apparatus, a feature also present in other ISs $[10,11]$. IS711 appears to duplicate the dinucleotide TA of the consensus target site, YTAR [7].

IS711 is exclusively present in the genome of all described species of the genus Brucella. The sequenced genomes of closely related $\alpha$-proteobacteria do not contain an IS obviously related to IS711, suggesting that this insertion sequence is an element native to the genus Brucella. Furthermore IS711 has been shown to be associated with the repeated elements BRU-RS1 and BRU-RS2 that could represent insertion hot spots for this IS $[12,13]$.

Some published work already suggested that IS711 could be an active transposon [14]. The copy number of IS711 is different in the species of the genus. B. melitensis has 7 copies of this element; the same number as $B$. abortus and B. suis. However, B. ovis contains about 35 copies $[7,8]$, and the recently discovered Brucella from marine mammals carry more than 20 IS711 copies [15]. Furthermore, the finding of a new IS711 copy inactivating the wboA gene in the vaccine strain RB51[14] also indicated that IS711 could be an active element. However, there is no experimental evidence of IS711 transposition up to now. Due to its proven genomic stability, IS711 has been used as a target to identify Brucella species and biovars $[12,16]$.

Other ISs have been described in Brucella in addition to IS711, such as the elements named ISBm1, ISBm2 and ISBm3 [17] and ISBm4 [18], as well as IS2020, which forms part of the composite transposon Tn2020 [19], but the mobility of these elements has not been observed experimentally.

In this study we report evidence for IS711 transposition from $B$. ovis and B. pinnipedialis by using PGBG1, a plasmid for isolating mobile DNA elements [20]. This constitutes the first experimental report of activity of a transposon in the genus Brucella.

\section{Results and discussion \\ Isolation and characterisation of tetracycline resistant derivatives of PGBGI in Brucella}

The transposon trap plasmid pGBG1 was introduced into Brucella by conjugation as described in the Materials and Methods. Plasmid PGBG1 carries a tetracycline resistance gene whose transcription is blocked by the repressor of bacteriophage lambda. Insertions of resident transposons into the repressor gene result in transcription of the $\mathrm{Tc}^{\mathrm{R}}$ gene of PGBG1 and can be selected on tetracycline containing media. As a preliminary step for the transposition experiments, we determined the stability of pGBG1 and the MIC of tetracycline for the different Brucella species to be used, since this plasmid had not been employed before in this genus. As result of these studies we found that Brucella strains must be grown in the presence of chloramphenicol in order to maintain pGBG1, and also determined that the most appropriate tetracycline concentration to avoid the appearance of spontaneous mutants in plasmid free Brucella was $30 \mu \mathrm{g} \mathrm{ml}^{-1}$. To assay for transposition, various independent colonies (10-20) of each Brucella strain carrying pGBG1 were grown in appropriate media. Cultures $(0.1 \mathrm{ml})$ were then plated separately on agar plates with $30 \mu \mathrm{g} \mathrm{ml}^{-1}$ of tetracycline or with $25 \mu \mathrm{g} \mathrm{ml}^{-}$ 1 of chloramphenicol (after dilution), and incubated at $37^{\circ} \mathrm{C}$ in $5 \% \mathrm{CO}_{2}$ atmosphere until growth was observed.

The frequencies of occurrence of tetracycline resistant colonies relative to chloramphenicol resistant CFU's ranged from $10^{-7}$ to $10^{-9}$, depending on the strain (Table 1 ). To determine whether the appearance of tetracycline resistant colonies was due either to transposition into pGBG1 of a Brucella transposon or to any other mutational event, selected colonies from each independent experiment were analysed by PCR using the primers G11 and G12 (Fig. 1, Table 2), which amplified the selection cartridge of

Table I: Frequencies of appearance of $\mathrm{Tc}^{\mathrm{R}}$ mutants in Brucella containing PGBG I

\begin{tabular}{|c|c|c|c|c|c|}
\hline Strain & $\begin{array}{l}\text { Frequency of } T c^{R} \\
\text { mutants* }\end{array}$ & $\begin{array}{l}\text { Number of } T c^{R} \\
\text { mutants analysed }\end{array}$ & $\begin{array}{l}\text { Number of mutants } \\
\text { with insertions }\end{array}$ & $\begin{array}{c}\% \text { of insertions } \\
\text { detected }\end{array}$ & $\begin{array}{c}\text { Mobile element } \\
\text { involved }\end{array}$ \\
\hline B. ovis $\mathrm{BOC} 22$ & (20) $8.6 \times 10^{-8}$ & 52 & 30 & 57.7 & IS7II \\
\hline B. abortus RB5I & (I0) $2.9 \times 10^{-9}$ & 46 & 0 & 0 & none \\
\hline B. melitensis $16 \mathrm{M}-\mathrm{N}$ & (10) $3.05 \times 10^{-7}$ & 13 & 0 & 0 & none \\
\hline B. pinnipedialis B2/94 & (I0) $5.0 \times 10^{-8}$ & 35 & 4 & 11.4 & IS7II \\
\hline
\end{tabular}

* Average frequency of all experiments. The number of independent experiments is in parentheses 


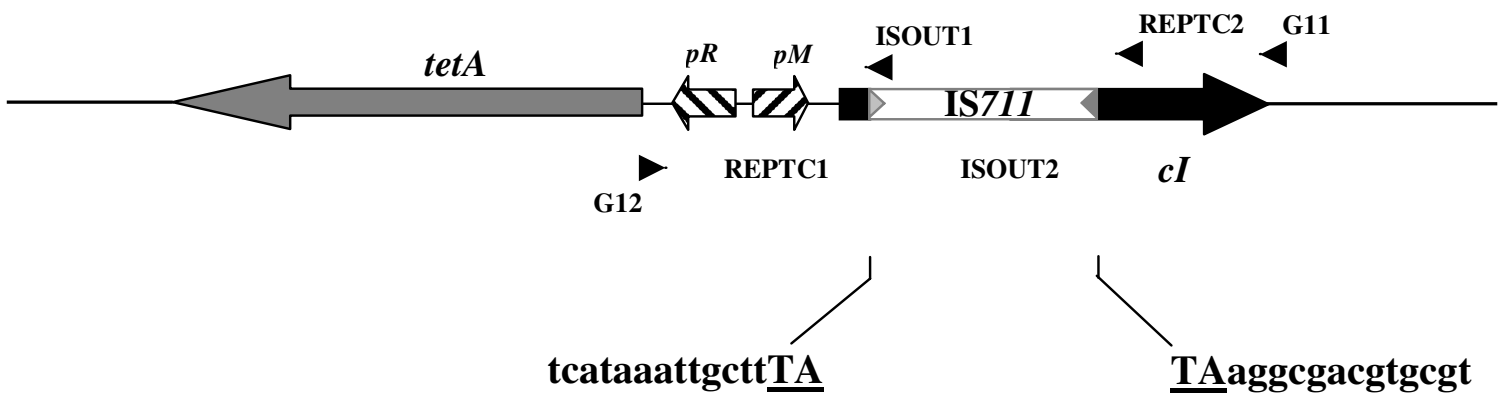

\section{Figure I}

Schematic drawing showing the selection cartridge of the plasmid pGBG I after the insertion of IS7 I I. Brucella strains containing these plasmids were resistant to tetracycline. The IS7 I I insertion is represented by a white box flanked by grey arrowheads. The target sequence is indicated and the duplicated bases appear as underlined capital letters. The primers used to amplify and determine the precise location of insertions in the selection cartridge are indicated with the primer name and black arrow heads.

pGBG1 plasmid as a $1.2 \mathrm{~kb}$ fragment. Some of the tetracycline resistant isolates produced a PCR amplification fragment of around $2.0 \mathrm{~kb}$. The size of these DNA fragments represented an increase of approximately $0.8 \mathrm{~kb}$ relative to the size of the target region of pGBG1, which was consistent with the integration of a copy of IS711 into the repressor controlling the tetracycline resistance gene of pGBG1. From the four Brucella strains in which the transposon trap pGBG1 was used, only B. ovis BOC22 and B. pinnipedialis $\mathrm{B} 2 / 94$ produced tetracycline resistant plasmids containing insertions (Fig. 2). No tetracycline resistant colonies containing insertions in the experiments that used B. abortus or B. melitensis as hosts were obtained. Some tetracycline resistant colonies were obtained with these two donors. PCR analysis of the corresponding plasmids in these cases, (and in some colonies from B. ovis and $B$. pinnipedialis as well) could not be explained by integration events. These resistant mutants probably resulted from point mutations (when the size of target region was apparently unchanged) or from deletions (when the size of target region decreased) in the pGBG1 selection cartridge (Fig. 1).

\section{Identification of IST I I in PGBGI TcR insertions}

As a first step towards identification of the DNA inserted into the tetracycline resistant insertional mutants, the PCR products were digested with the restriction enzyme HaeIII. Six different restriction patterns were observed, four in $B$. ovis BOC22 (C, D, E and F) and two in B. pinnipedialis B2/ 94 (A and B, Fig. 3A).

To confirm whether the insertions were due to integration of IS711 into pGBG1, the HaeIII digested PCR products containing insertions were transferred to a nylon membrane and hybridised with an IS711 probe. Southern hybridisation analysis showed that all insertions in pGBG1 were due to the presence of IS711 (Fig. 4).

The different restriction patterns obtained with HaeIII could indicate that the IS had inserted in different posi-

Table 2: Oligonucleotide primers

\begin{tabular}{lll}
\hline Primer name & Sequence 5'-3' & Reference \\
\hline $71 \mathrm{lu}$ & CACAAGACTGCGTTGCCGACAGA & This study \\
$71 \mathrm{ld}$ & CATATGATGGGACCAAACACCTAGGG & This study \\
GII & TATCAGCTATGCGCCGACCAGAAC & {$[20]$} \\
GI2 & GCCAATCCCCATGGCATCGAGTAA & {$[20]$} \\
REPTCI & GGCGTTATAAGCATTTAATG & This study \\
REPTC2 & AAAAAGAAACCATTAACACA & This study \\
ISOUTI & GCGGCCGGGCGTACCAACTCG & This study \\
ISOUT2 & GCTATCGTCGTATTGCGCTGC & This study \\
\end{tabular}




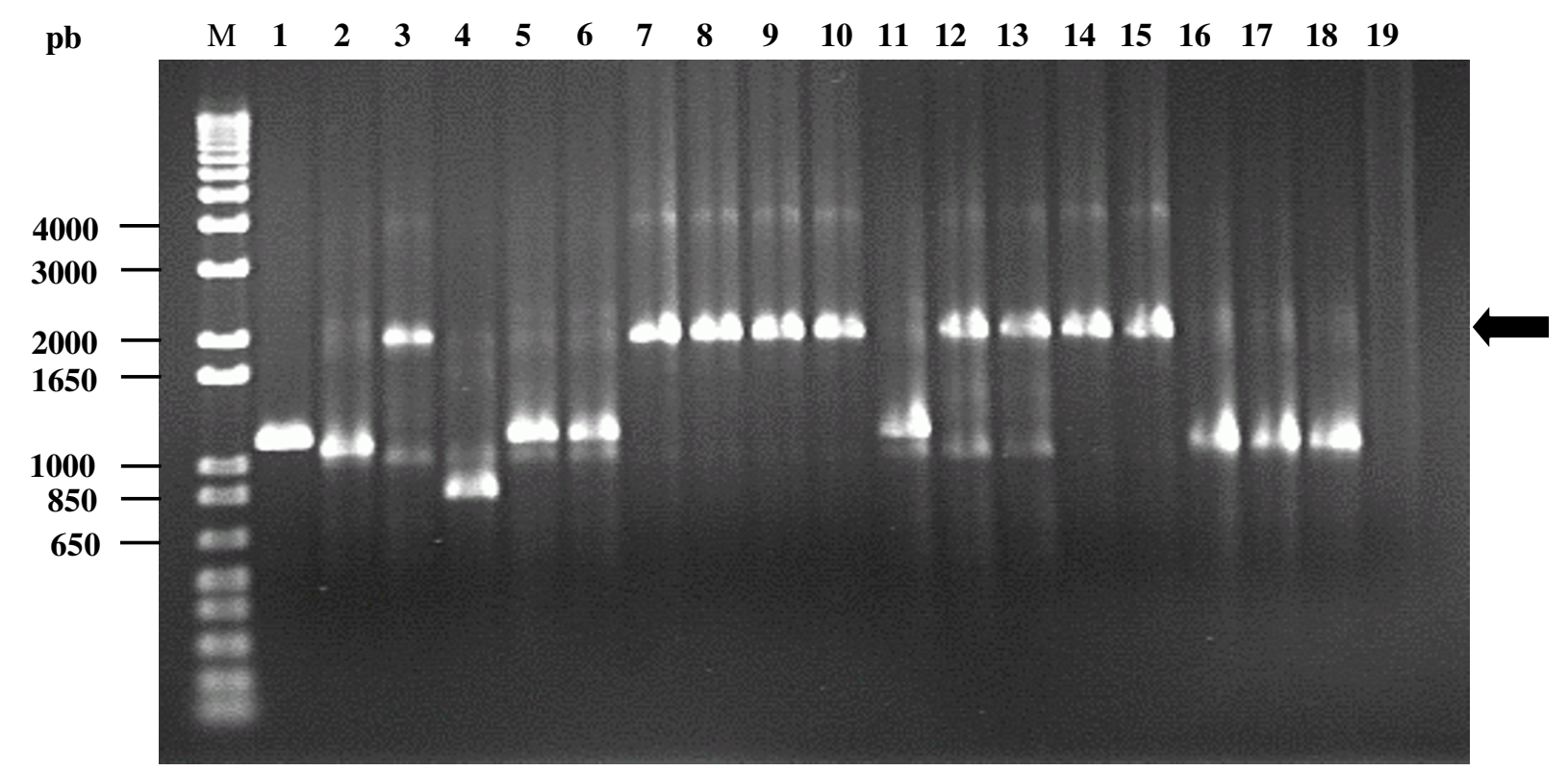

\section{Figure 2}

PCR analysis of the plasmids found in tetracycline resistant mutants. PCR with primers GII and GI2 was carried out in order to amplify the selection cartridge of PGBGI in tetracycline resistant mutants obtained in Brucella. The black arrow indicates the position of the PCR fragment obtained from PGBGI/TcR mutants due to insertions encountered in $B$. ovis $B O C 22$ and B. pinnipedialis B2/94 strains (Lanes 3, 7, 8, 9, 10, 12, I3, 14 and I5). Mutants due to deletions and point mutations (Lanes 2, $4,5,6, I I, 16,17$ and I8) produced PCR products of the same size or smaller than the vector pGBG I (Lane I). M: Molecular Weight Marker I Kb plus DNA Ladder. I. Lane 19. Negative control (PCR reaction mixture without DNA).

tions of the target gene, but could also be the result of IS711 sequence polymorphism in B. ovis and B. pinnipedialis, as both species are poorly characterised. In order to clarify this point, the PCR products obtained from selected tetracycline resistant insertional mutants (pGBG1::IS711) were purified and sequenced with the ISOUT1/ISOUT2, and the REPTC1/REPTC2 pairs of primers (Fig. 1 and Table 2).

\section{Sequence analysis of the IS7 I I inserted copies}

Twenty one PCR products from pGBG1::IS711 tetracycline resistant mutants were selected to determine the complete sequence of the IS711 copy which integrated into $c I$ gene. The sequence analysis showed that all the IS711 insertions had taken place at the same point within the $c I$ gene, near its 5 ' terminal end. In all cases the insertion occurred at the sequence TTAA according to the predicted IS711 target. The central dinucleotide TA was duplicated at both sides of the element as was expected. IS711 insertions at this point occurred in the two possible orientations. It was surprising to find that all the IS711 insertions occurred in the same point of the $c$ I gene. Trans- posons vary in the degree of target specificity from highly specific (i.e. $\operatorname{Tn} 7)$ to near random insertion transposons [21]. The observance of a single insertion site among 40 independent transposition experiments indicated a strong degree of specificity in target selection. The reported target for IS711 integration was the very frequent YTAR sequence. However, a preference for insertion of IS711 into the Bru-RS palindromic repeats has also been reported, indicating the existence of some undetermined determinants of integration specificity. Our experimental system can only detect insertions into the $1 \mathrm{~kb} c \mathrm{I}$ gene, which contains around fifteen YTAR sites. The reason for the observed transposition preference for a single site remains unexplained.

Sequence analysis indicated the presence of four different copies of IS711 disrupting the $c I$ gene. Each copy was designated with a different nomenclature: IS711-IsoA, IS711IsoB, IS711-IsoC and IS711-IsoD. Nucleotide sequences of these IS711 copies were compared with the copy named IS711A from B. ovis (GenBank Accession number: M94960). The copy designated as IS711-IsoB was identi- 
A

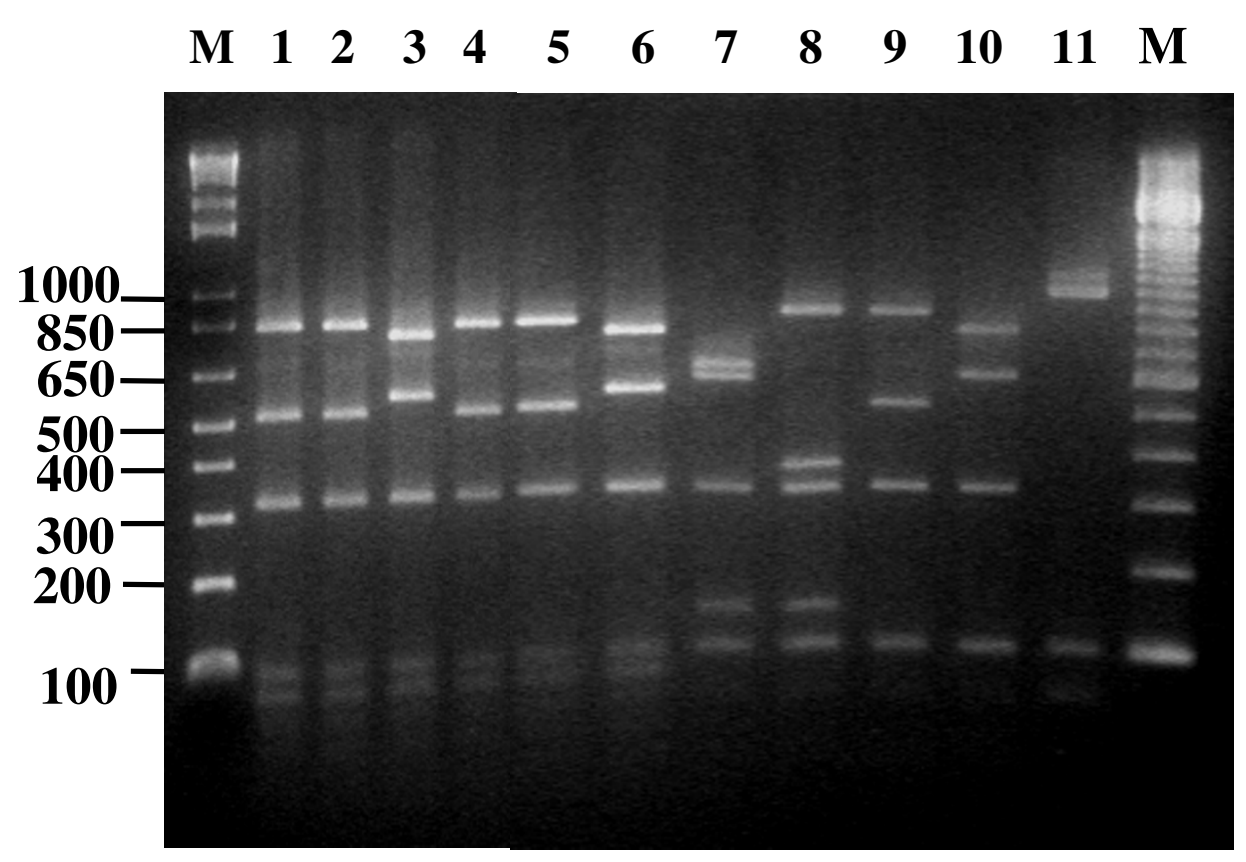

$\begin{array}{llllllllll}\mathbf{A} & \mathbf{A} & \mathbf{B} & \mathbf{A} & \mathbf{A} & \mathbf{B} & \mathbf{C} & \mathbf{D} & \mathbf{E} & \mathbf{F}\end{array}$

B

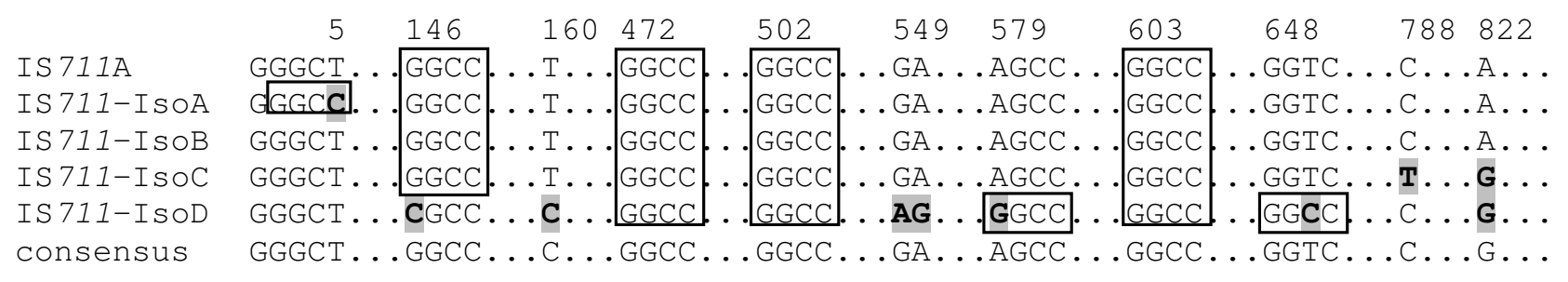

Figure 3

Diversity of restriction profiles and nucleotide sequence of IS7 I I copies recovered in IS7 I I insertions in pGBG I. A) PCR products from several PGBGI/TC $c^{R}$ mutants digested with Haelll. Lanes I to 6 contain insertions obtained in B. pinnipedialis B2/94. Lanes 7-10 insertions obtained in B. ovis BOC22 Lane II, PCR product from pGBG I. M: Molecular size marker (I Kb DNA ladder, Invitrogen). Letters under the picture indicate the different restriction patterns obtained. In B) the nucleotide sequences of the IS7 I I copies transposed into $\mathrm{cl}$ lambda repressor gene were compared with IS7 I IA from B. ovis

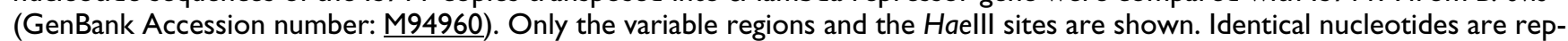
resented by dots. Numerals in the top indicate the positions where nucleotide changes occur. Nucleotide substitutions are boldface and shaded. The Haell restriction sites are indicated within open boxes. 


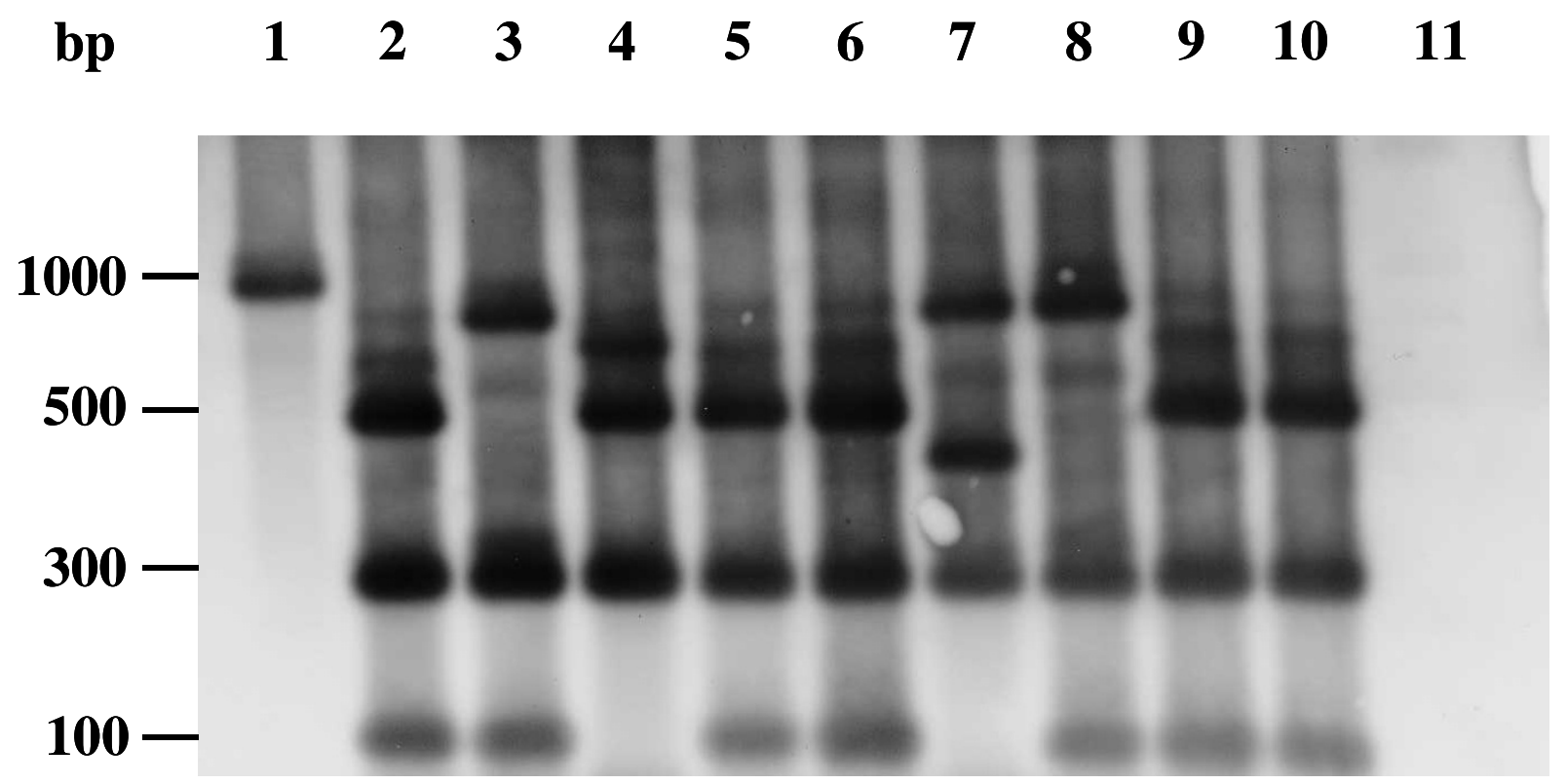

\section{Figure 4}

Southern blot hybridisation of amplified regions from $\mathrm{Tc}^{\mathrm{R}}$ mutants showing the insertion of IS7 II. PCR products obtained with primers GII and GI 2 from several $P$ GBG I/Tc ${ }^{R}$ insertion mutants were digested with Haelll and hybridised with an IS7 I I probe. Lane I: IS7 I I probe, lanes 2-I0: insertion mutants containing IS7 I I, lane I I: PCR product from pGBG I. Molecular sizes of the fragments are indicated in bp.

cal to IS711A. Differences between other IS711 copies were due to a few nucleotide substitutions that in some cases led to the appearance or disappearance of some of HaeIII restriction sites (Figure $3 \mathrm{~b}$ ). These sequence differences were responsible of the remaining diversity in HaeIII digestions shown in Fig. 3. Some of these nucleotide changes were silent and the putative transposases of the different IS711 copies were identical to that of IS711A, with the exception of IS711-IsoD which was different to other copies by 3 amino acids which were Gly in place of Arg, Lys replacing Glu and Val instead of Ala.

These results demonstrate that some of the IS711 copies in $B$. ovis and $B$. pinnipedialis were transpositionally active even when the observed transposition frequency was very low. We were unable to precisely determine transposition frequencies with this assay but if we consider that the tetracycline resistant colonies selected for analysis were representative of the whole population, we know that $57.7 \%$ of the mutants obtained in $B$. ovis and $11.4 \%$ of those obtained in B. pinnipedialis were due to IS711 transposition (Table 1). These percentages allowed us to estimate the average transposition frequency around $10^{-8}$ in both species. These frequencies are low when compared with other transposons.

\section{Transposition activity of IS7 I I}

Transposition of IS711 was detected only in B. ovis and B. pinnipedialis. We were unable to detect transposition either in B. abortus or in B. melitensis under the same experimental conditions. Many attempts to detect IS711 transposition in E. coli from plasmids containing cloned copies of IS711 were also unsuccessful, even when powerful detection systems as the $s a c B$ transposon trap [22] were used (data not shown). All these data indicated that IS711 transposition activity was very low, restricted to Brucella maybe due to the requirement for specific host factors, and only detectable in species with a high number of copies of IS711 per genome. The presence of some IS711 copies in these species encoding a full length transposase without the need for a frameshift event, could explain the observed transposition capability. However, such a copy of IS711 has not been observed in the genomic sequence of $B$. ovis released recently to GenBank and a gene dosage 

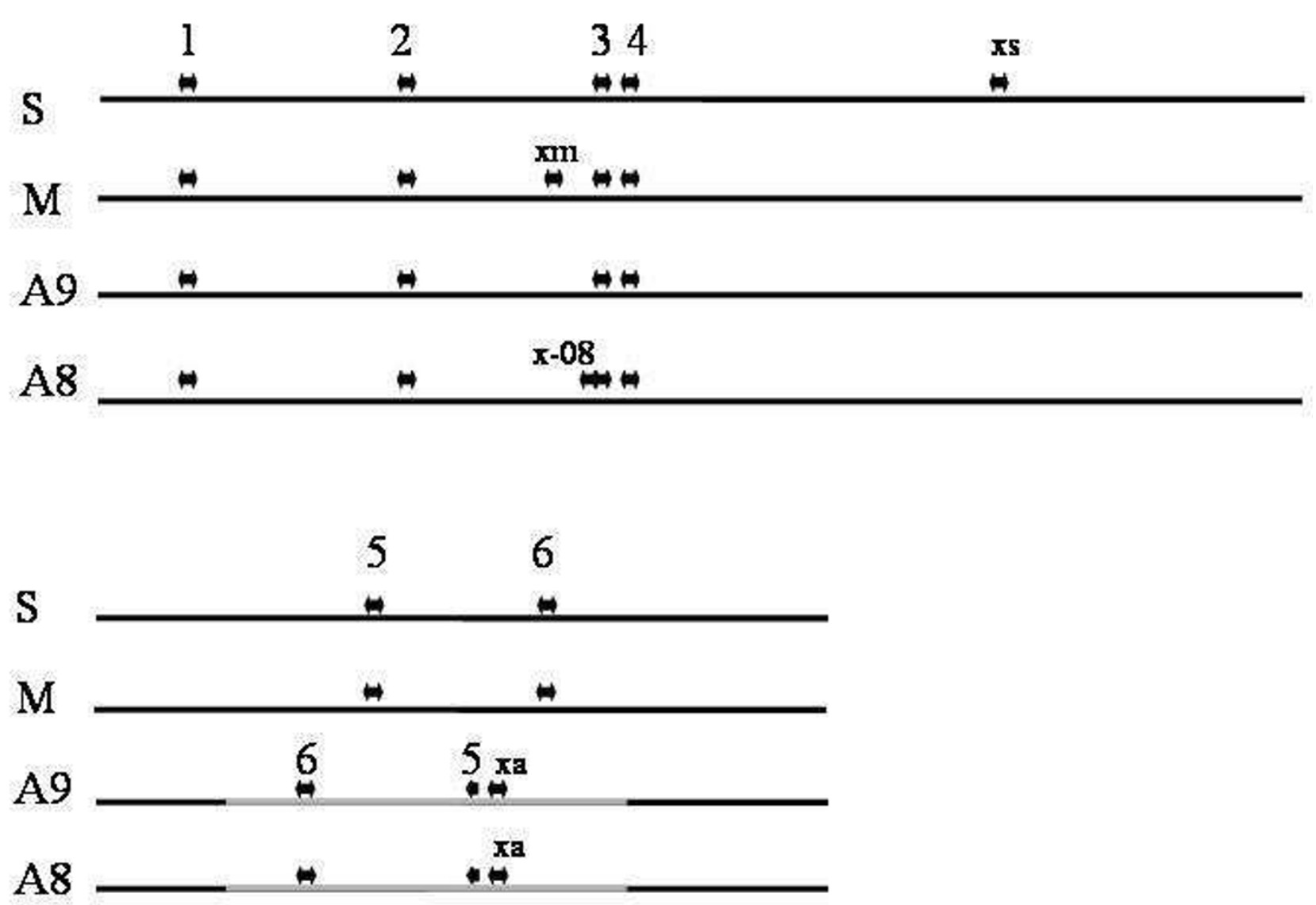

Figure 5

Position of IS7 I I copies in the chromosomes of the published Brucella genomes. The two blocks contain the large and the small chromosomes respectively. Key to the species: S, B. suis; $M$, B. melitensis; A9, B abortus 9_94I; A8, B abortus 2308; $\mathrm{O}, \mathrm{B}$. ovis. Common copies numbered from I to 6 are marked on the top. xs, xiii, $x-08$ and xa are IS7I I species specific copies. The inverted segment of $B$. abortus chromosome II is marked in grey.

effect is a more favoured hypothesis for transposition in $B$. ovis and B. pinnipedialis. The requirement for many copies of the IS could be due either to a very low level of expression of the transposase, requiring an increased dose effect for activity, or to the presence of point mutations leading to inactivity of some of the copies found in B. abortus and $B$. melitensis. There are several reasons that could explain a low level of IS711 transposase expression. Firstly, that the regular initiation codon for IS711 OrfA is GTG, a less efficient initiation codon than the canonic ATG. Secondly, that a -1 frameshift could be necessary in order to have an active IS711 transposase molecule. This event is usually very inefficient with less than $5 \%$ of the translation products shifted to translate into the complete transposase. Furthermore, in some insertion sequences OrfA possesses an inhibitory action on the transposition process [23].
We examined the nucleotide sequence of the IS711 copies in the genomes of the three sequenced Brucella species and analysed them to detect the reasons for their inactivity. In some of the copies either OrfA or OrfB were truncated or altered by single nucleotide insertions or deletions. Furthermore, we found that in many of these copies the start codon for OrfA was TTG instead of GTG as happens in all the copies rescued after inactivation of the $c I$ repressor in pGBG1. TTG has been reported to be less efficient than GTG as a translation initiation codon [24]. These data support that the lack of activity observed in B. abortus and $B$. melitensis as well as the low transposition frequency observed in $B$. ovis and B. pinnipedialis could be due to the low expression (translation) of the IS711 transposase protein. 
Table 3: Bacterial strains and plasmids used in this study

\begin{tabular}{|c|c|c|}
\hline Strain/Plasmid & Relevant characteristics & Reference \\
\hline \multicolumn{3}{|l|}{ E. coli strains } \\
\hline SI7.I & $\mathrm{Tp}^{\mathrm{R}} \mathrm{Sm}^{\mathrm{R}}$, recA, thi, pro, hsdR-M+ RP4: 2-Tc:Mu: Km Tn7 $\lambda$ pir & {$[30]$} \\
\hline \multicolumn{3}{|l|}{ Brucella strains } \\
\hline B. abortus RB5I & RifR, rough mutant of 2308 & {$[3 \mid]$} \\
\hline B. melitensis I6M-N & Spontaneous $\mathrm{Nal}^{\mathrm{R}}$ mutant of ATCC 23456 & This study \\
\hline B. ovis BOC 22 & Rough field strain, $\mathrm{CO}_{2}$ dependent & This study \\
\hline B. pinnipedialis B2/94 & Brucella marine strain isolated from common seal, $\mathrm{CO}_{2}$ dependent & [32] \\
\hline \multicolumn{3}{|l|}{ Plasmids } \\
\hline PGBGI & $\mathrm{Cm}^{\mathrm{R}}$, transposon trap derivative of $\mathrm{pBBR}-\mathrm{MCSI}$ & {$[20]$} \\
\hline
\end{tabular}

$\mathrm{Cm}^{\mathrm{R}}$ : Chloramphenicol resistant, Nal ${ }^{R}:$ Nalidixic acid resistant, Rif ${ }^{R}:$ Rifampicin resistant, $T p^{R}:$ Trimethoprim resistant, Sm ${ }^{R}:$ Streptomycin resistant,

\section{Distribution and analysis of IS7 I I in the Brucella sequenced genomes}

The reported sequence of IS711 [7], (GenBank accession $\underline{\text { M94960) }}$ was compared with the available Brucella genomic sequences using local BLAST searches. The results showed the presence of 7 IS711 copies in $B$. suis and B melitensis. B abortus 9_941 also presented 7 IS711 copies but one of them was severely truncated and reduced to a 100 bp terminal remnant. B. abortus 2308 contained the same IS711 copies as the strain 9_941 and one additional IS711 copy located at exactly the same position as one of the pre-existing copies. It is well known that the $B$. abortus vaccine strain RB51, which is a derivative of 2308, contains an extra copy of IS711 interrupting the $w b o A$ gene [14].

The genome of B. ovis was known to contain a high copy number of IS711 estimated by hybridisation in around 30 copies [8]. The genome sequence of this species has been recently deposited in GenBank (Accesion Numbers $\underline{\mathrm{CP} 000708}$ and $\underline{\mathrm{CP} 000709}$ ). Genome sequence analysis revealed the presence of 38 complete copies of IS711 in the $B$. ovis genome, 25 and 13 in each chromosome respectively. Upon analysis of the genomic location of the IS711 copies we could determine that the position of six out of the seven copies was conserved in all the Brucella species. Four of the conserved copies were found in the large chromosome and two in the small chromosome. The common copies will be numbered from 1 to 6 plus a species or strain identifier (Fig. 5). When the nucleotide sequence of individual IS copies was analyzed it was evident that some sequence divergence existed among them. This indicated that IS sequence had drifted along with the other chromosomal genes in Brucella. At the same time this sequence variation allowed us to interpret the sequence identity between IS copies in the same organism as an indicator of recent transposition. In $B$. abortus the extra copy 711_xa was found to be identical to 711_1a. In B. abortus 2308 there is an additional IS711 copy found next to 711_3a. This copy was also identical to 711_1a. These observations strongly suggest that IS711_1a could be active and also show the strong preference of IS711 to transpose to some sites on the genome. On the other hand the IS711 copy found in the wboA gene of the B. abortus vaccine strain RB51 was found to be identical to 711_a6. This finding was rather unexpected, since 711_a6 lacks the first five nucleotides from the left IR, which would usually result in loss of the transposition ability. Insertion of this copy of IS711 into the wboA gene could also be explained by a different mobility mechanism other than transposition.

If we correlate the sequence analysis with the results presented in this study, we can conclude that the natural transposition of IS711 occurs at very low frequency, probably due to a poor expression of IS711 transposase. This limitation can be overcome in B. ovis by the high copy number of IS711.

\section{Conclusion}

In conclusion, our results demonstrate experimentally for the first time that IS711 is an active insertion sequence of the Brucellae. On the other hand, the low transpositional activity of the sequence allows the use of this element as a tool for molecular identification, at least for the species containing a low number of copies of this insertion sequence.

\section{Methods}

\section{Bacterial strains plasmids and growth conditions}

The bacterial strains and plasmids used in this study are listed in Table 3. Escherichia coli cells were cultivated overnight at $37^{\circ} \mathrm{C}$ in Luria-Bertani (LB) medium (Pronadisa). Brucella strains were grown at $37^{\circ} \mathrm{C}$ for $48-96$ hours in a 
$5 \% \mathrm{CO}_{2}$ atmosphere in Brucella broth (BB) (Pronadisa), Blood agar (Difco) or Brucella agar (BA) medium (Pronadisa). Plates were supplemented with $10 \%$ foetal bovine serum to grow B. ovis and B. pinnipedialis.

pGBG1 (courtesy of $\mathrm{M}$. Blot), is a derivative from the broad host-range, mobilizable plasmid pBBR1-MCS [25] containing a transposition selection module with a tetracycline resistance gene (tet $A$ ) whose expression is blocked by $\lambda$ repressor $c I$. This plasmid allows positive selection for tetracycline resistance of transposon insertions inactivating the repressor [20].

\section{General DNA manipulations, PCR and Southern blot hybridisations}

DNA preparations, purifications, restriction endonuclease digestions and agarose gel electrophoresis were carried out according to described standard protocols [26].

Oligonucleotide primers used in this study were purchased from MWG Biotech and are listed in Table 2. PCR reactions were usually performed in $25 \mu \mathrm{l}$ reaction volumes containing $0.2 \mu \mathrm{M}$ of each primer, $2.5 \mu \mathrm{l}$ of $10 \times$ PCR reaction buffer, $1.5 \mathrm{mM}$ of $\mathrm{MgCl}_{2}, 0.2 \mathrm{mM}$ of dNTPs (Applied Biosystems), $25 \mathrm{ng}$ of template DNA and 1 unit of BioTaq DNA polymerase (Bioline). Amplification was performed in a thermal cycler (GeneAmp PCR System 2400, Perkin Elmer) as follows: denaturation step at $94^{\circ} \mathrm{C}$ for $3 \mathrm{~min}$ and 25 cycles of $94^{\circ} \mathrm{C}$ for $30 \mathrm{~s}, 50^{\circ} \mathrm{C}$ for $30 \mathrm{~s}$ and $72^{\circ} \mathrm{C}$ for $1 \mathrm{~min}$. After the last cycle the reaction mixture was reincubated at $72^{\circ} \mathrm{C}$ for $5 \mathrm{~min}$.

Preparation of the IS711 probe was performed by PCR amplification with two primers, $711 \mathrm{u}$ and $711 \mathrm{~d}$, using genomic DNA from $B$. melitensis $16 \mathrm{M}$ as template. The PCR reaction was carried out as described and the amplified DNA fragment to be used as a probe was recovered from an agarose gel by using the QIAquick Gel Extraction Kit (QIAGEN). The probe was labelled with digoxigenin using a DIG-High Prime DNA Labelling and Detection Kit (Roche Diagnostics $\mathrm{GmbH}$ ) as described by the supplier. Southern blot hybridisation with the DIG-labelled probe was performed as described before [27].

\section{Conjugation experiments}

Introduction of plasmid pGBG1 into Brucella was performed by conjugation from E. coli S17.1. The experiments were carried out by filter mating as follows. Equal volumes $(500 \mu \mathrm{l})$ of mid-log-phase cultures of E. coli S.17 (pGBG1) as donor and B. abortus RB51, B. melitensis 16M$\mathrm{N}$, B. ovis BOC22 or B. pinnipedialis B2/94 as recipients were mixed and then washed with sterile PBS by centrifugation. The mixtures were spread on $0.22 \mu \mathrm{m}$ filters $(24$ mm diameter, GSWP, Millipore), placed on a Brucella agar plate and incubated at $37^{\circ} \mathrm{C}$ for $12 \mathrm{~h}$ in $5 \%$
$\mathrm{CO}_{2}$ atmosphere. After this period of incubation the filters with the conjugation mixtures were washed in $3 \mathrm{ml}$ of $\mathrm{BB}$ medium. Different serial dilutions $\left(10^{-1}-10^{-3}\right)$ of the conjugation mixtures were plated onto the appropriated media until growth was observed. The transconjugants of B. melitensis $16 \mathrm{M}-\mathrm{N}$ and B. abortus RB51 were selected on Brucella agar medium with chloramphenicol $\left(25 \mu \mathrm{g} \mathrm{ml}^{-1}\right)$ and either nalidixic acid $\left(20 \mu \mathrm{g} \mathrm{ml}^{-1}\right)$ or rifampicin $(50 \mu \mathrm{g}$ $\mathrm{ml}^{-1}$ ) respectively. Transconjugants of $B$. ovis BOC22 and B. pinnipedialis B2/94 strains were selected on BA medium supplemented with $10 \%$ of foetal bovine serum containing chloramphenicol ( $\left.25 \mu \mathrm{g} \mathrm{ml}^{-1}\right)$ and a mixture of antibiotics (vancomycin, $3 \mu \mathrm{g} \mathrm{ml}^{-1}$; colistin, $7.5 \mu \mathrm{g} \mathrm{ml}^{-1}$; nystatin 12.5 units $\mathrm{ml}^{-1}$ and nitrofurantoin $10 \mu \mathrm{g} \mathrm{ml}^{-1}$ ) to counterselect against the donors. The presence of pGBG1 in the transconjugants was confirmed by extraction of plasmid DNA and analysis on agarose gels.

\section{DNA sequencing and data analysis}

PCR products were purified for sequencing by using the QIAquick Gel Extraction Kit (QIAGEN). All PCR products were sequenced by our Sequencing Service using a commercial cycle sequencing kit (Perkin Elmer, Dye Terminator Cycle Sequencing Ready Fraction Kit) according to the manufacturer's conditions. Both, the nucleotide and protein sequence analysis of the different IS711 copies isolated from each Brucella strains were performed by using the Vector NTI version 5.5 computer program (Informax Inc.). Sequences were compared with the IS711 copies reported in GenBank with the BLAST sequence comparison tool [28].

Preliminary sequence data of the $B$. ovis genome was obtained from The Institute for Genomic Research [29]

\section{Authors' contributions}

AOS performed most of the experimental work and wrote a draft of the paper.

JMGL designed and supervised the experimental work and wrote the paper. Both authors have read an approved the final manuscript.

\section{Acknowledgements}

This work has been supported by grants from the "Instituto de Salud Carlos III" of the Spanish Ministry of Health to the "Network for Brucellosis research/G03-204" and PI05/2499. We thank M. Blot for providing PGBGI and C. Marín Alcalá for providing B. pinnipedialis strain B2/94.

\section{References}

I. Boschiroli ML, Foulongne V, O'Callaghan D: Brucellosis: a worldwide zoonosis. Curr Opin Microbiol 200I, 4:58-64.

2. DelVecchio VG, Kapatral V, Redkar RJ, Patra G, Mujer C, Los T, Ivanova N, Anderson I, Bhattacharyya A, Lykidis A, Reznik G, Jablonski L, Larsen N, D'Souza M, Bernal A, Mazur M, Goltsman E, Selkov E, Elzer PH, Hagius S, O'Callaghan D, Letesson J], Haselkorn R, Kyrpides $\mathrm{N}$, Overbeek $\mathrm{R}$ : The genome sequence of the facultative intra- 
cellular pathogen Brucella melitensis. Proc Natl Acad Sci U S A 2002, 99:443-448.

3. Paulsen IT, Seshadri R, Nelson KE, Eisen JA, Heidelberg JF, Read TD, Dodson RJ, Umayam L, Brinkac LM, Beanan MJ, Daugherty SC, Deboy RT, Durkin AS, Kolonay JF, Madupu R, Nelson WC, Ayodeji B, Kraul M, Shetty J, Malek J, Van Aken SE, Riedmuller S, Tettelin H, Gill SR, White O, Salzberg SL, Hoover DL, Lindler LE, Halling SM, Boyle SM, Fraser CM: The Brucella suis genome reveals fundamental similarities between animal and plant pathogens and symbionts. Proc Natl Acad Sci U S A 2002, 99: I 3 |48-13। 53.

4. Halling SM, Peterson-Burch BD, Bricker BJ, Zuerner RL, Qing Z, Li LL, Kapur V, Alt DP, Olsen SC: Completion of the genome sequence of Brucella abortus and comparison to the highly similar genomes of Brucella melitensis and Brucella suis. J Bacteriol 2005, 187:27|5-2726.

5. Chain PSG, Comerci DJ, Tolmasky ME, Larimer FW, Malfatti SA, Vergez LM, Aguero F, Land ML, Ugalde RA, Garcia E: WholeGenome Analyses of Speciation Events in Pathogenic Brucellae. Infect Immun 2005, 73:8353-836I.

6. Halling SM, Zehr ES: Polymorphism in Brucella spp. due to highly repeated DNA. J Bacteriol 1990, I 72:6637-6640.

7. Halling SM, Tatum FM, Bricker BJ: Sequence and characterization of an insertion sequence, IS7II, from Brucella ovis. Gene 1993, 133:123-127.

8. Ouahrani S, Michaux S, Sri Widada J, Bourg G, Tournebize R, Ramuz $M$, Liautard JP: Identification and sequence analysis of IS650I, an insertion sequence in Brucella spp.: relationship between genomic structure and the number of IS650 I copies. J Gen Microbiol I993, I39( I 2):3265-3273.

9. The IS Database [http://www-is.biotoul.fr]

10. Chandler M, Fayet O: Translational frameshifting in the control of transposition in bacteria. Mol Microbiol 1993, 7:497-503.

II. Sekine Y, Ohtsubo E: Frameshifting is Required for Production of the Transposase Encoded by Insertion Sequence I 10.1073/pnas.86.12.4609. Proceedings of the National Academy of Sciences 1989, 86:4609-46/3.

12. Cloeckaert A, Grayon M, Grepinet O: An IS7II element downstream of the bp26 gene is a specific marker of Brucella spp. isolated from marine mammals. Clin Diagn Lab Immunol 2000, 7:835-839.

13. Halling SM, Bricker BJ: Characterization and occurrence of two repeated palindromic DNA elements of Brucella spp.: BruRSI and Bru-RS2. Mol Microbiol 1994, I 4:68I-689.

14. Vemulapalli R, McQuiston JR, Schurig GG, Sriranganathan N, Halling SM, Boyle SM: Identification of an IS7 I I element interrupting the wboA gene of Brucella abortus vaccine strain RB5 I and a PCR assay to distinguish strain RB5 I from other Brucella species and strains. Clin Diagn Lab Immunol 1999, 6:760-764.

15. Clavareau C, Wellemans V, Walravens K, Tryland M, Verger JM, Grayon M, Cloeckaert A, Letesson J], Godfroid J: Phenotypic and molecular characterization of a Brucella strain isolated from a minke whale (Balaenoptera acutorostrata). Microbiology 1998, 144:3267-3273.

16. Bricker BJ, Halling SM: Differentiation of Brucella abortus bv. I, 2, and 4, Brucella melitensis, Brucella ovis, and Brucella suis bv. I by PCR. I Clin Microbiol 1994, 32:2660-2666.

17. Godfroid F, Taminiau B, Danese I, Denoel P, Tibor A, Weynants V, Cloeckaert A, Godfroid J, Letesson J]: Identification of the perosamine synthetase gene of Brucella melitensis $16 \mathrm{M}$ and involvement of lipopolysaccharide $\mathbf{O}$ side chain in Brucella survival in mice and in macrophages. Infect Immun 1998, 66:5485-5493.

18. Godfroid F, Cloeckaert A, Taminiau B, Danese I, Tibor A, de Bolle X, Mertens $P$, Letesson J]: Genetic organisation of the lipopolysaccharide $O$-antigen biosynthesis region of brucella melitensis I 6 M (wbk). Res Microbiol 2000, 15 1:655-668.

19. Halling SM, Zuerner RL: Evidence for lateral transfer to Brucellae: characterization of a locus with a Tn-like element (Tn2020). Biochim Biophys Acta 2002, 1574:109-116.

20. Schneider D, Faure D, Noirclerc-Savoye M, Barriere AC, Coursange $\mathrm{E}$, Blot M: A broad-host-range plasmid for isolating mobile genetic elements in gram-negative bacteria. Plasmid 2000, 44:20I-207.

21. Craig NL: Target site selection in transposition. Annu Rev Biochem 1997, 66:437-474.
22. Gay P, Le Coq D, Steinmetz M, Berkelman T, Kado Cl: Positive selection procedure for entrapment of insertion sequence elements in gram-negative bacteria. J Bacteriol 1985, 164:918-921.

23. Sekine Y, Izumi K, Mizuno T, Ohtsubo E: Inhibition of transpositional recombination by OrfA and OrfB proteins encoded by insertion sequence IS3. Genes Cells 1997, 2:547-557.

24. O'Donnell SM, Janssen GR: The Initiation Codon Affects Ribosome Binding and Translational Efficiency in Escherichia coli of cl mRNA with or without the 5' Untranslated Leader. J Bacteriol 200I, 1 83:1277-I283.

25. Antoine $R$, Locht $C$ : Isolation and molecular characterization of a novel broad-host-range plasmid from Bordetella bronchiseptica with sequence similarities to plasmids from grampositive organisms. Mol Microbiol 1992, 6:1785-1799.

26. Sambrook J, Maniatis T, Fritsch EF: Molecular cloning : a laboratory manual. 2nd edition. Cold Spring Harbor, N.Y., Cold Spring Harbor Laboratory; 1989:3 v..

27. Ocampo-Sosa AA, Agüero-Balbín J, García-Lobo JM: Development of a new PCR assay to identify Brucella abortus biovars 5, 6 and 9 and the new subgroup 3b of biovar 3. Vet Microbiol 2005, I I 0:4I-5I.

28. Altschul SF, Gish W, Miller W, Myers EW, Lipman DJ: Basic local alignment search tool. J Mol Biol 1990, 215:403-410.

29. The Institute for Genomic Research [http://www.tigr.org]

30. Simon R, Priefer U, Pühler A: A broad host range mobilization system for in vivo genetic engineering, transposon mutagenesis in Gram negative bacteria. Bio/Technology 1983, 1:784-79|.

31. Schurig GG, Roop RM 2nd, Bagchi T, Boyle S, Buhrman D, Sriranganathan $\mathrm{N}$ : Biological properties of RB5 I; a stable rough strain of Brucella abortus. Vet Microbiol |99|, 28:|7|-|88.

32. Foster G, Jahans KL, Reid RJ, Ross HM: Isolation of Brucella species from cetaceans, seals and an otter. Vet Rec 1996, 138:583-586.
Publish with Bio Med Central and every scientist can read your work free of charge

"BioMed Central will be the most significant development for disseminating the results of biomedical research in our lifetime."

Sir Paul Nurse, Cancer Research UK

Your research papers will be:

- available free of charge to the entire biomedical community

- peer reviewed and published immediately upon acceptance

- cited in PubMed and archived on PubMed Central

- yours - you keep the copyright

Submit your manuscript here:

http://www.biomedcentral.com/info/publishing_adv.asp
BioMedcentral 